\title{
A IMPORTÂNCIA DO USO DE JOGOS DIDÁTICOS COMO MÉTODO FACILITADOR DE APRENDIZAGEM
}

\author{
Juliana Pacheco Ventura' ${ }^{1}$ \\ Sílvia Kátia de Souza Ramanhole ${ }^{2}$ \\ Monique Moreira Moulin ${ }^{3}$
}

\begin{abstract}
Resumo: O processo de assimilação e apropriação dos conteúdos de Ciências e Biologia é considerado por muitos alunos de diferentes níveis de ensino como algo muito complexo e de difícil absorção. Diante disso, faz-se necessário que o professor disponha de outros métodos que o auxiliem e que facilitem o entendimento do conteúdo por parte dos alunos. Acredita-se que a implementação de novas práticas educativas, dentre estas se destaca o emprego de estratégias de ensino diversificadas, podem ajudar na superação dos obstáculos e na reversão dos problemas que afligem a área da educação. Desta forma, objetivou-se com esta pesquisa avaliar a contribuição de um jogo didático na assimilação e apropriação do conteúdo ministrado na terceira série do ensino médio referente a Taxonomia e Sistemática na E.E.E.F.M. "Sirena Rezende Fonseca".

Palavras-chave: Assimilação; Conhecimentos; Jogos didáticos.
\end{abstract}

\footnotetext{
1 Estudante de Licenciatura em Ciências Biológicas/Instituto Federal do Espírito Santo - Campus de Alegre, Brasil. E-mail: julianaventura07@gmail.com.

2 E.E.E.F.M. "Sirena Rezende Fonseca, Brasil. E-mail: silviasouza748@gmail.com.

${ }^{3}$ Instituto Federal do Espírito Santo - Campus de Alegre, Brasil. E-mail: mmmoulin@ifes.edu.br.
} 